\title{
Dynamic flood webmapping: an operational and cost-limited tool to optimize crisis management
}

\author{
Quentin Strappazzon ${ }^{1, a}$, Arnaud Koch ${ }^{1}$, Loïck Guesdon ${ }^{2} \&$ Marc Delbec $^{1}$ \\ ${ }^{1}$ Prolog Ingénierie - 11, rue Auguste Lacroix, 69003 Lyon, France \\ ${ }^{2}$ SyAGE (Syndicat mixte pour l'Assainissement et la Gestion des Eaux du bassin versant de l'Yerres) - 17, Rue Gustave Eiffel, 91230 \\ Montgeron, France
}

\begin{abstract}
Due to strong climate variations and the multiplication of flood events, protection based strategies are no longer sufficient to handle a watershed scale crisis. Monitoring, prediction and alert procedures are required to ensure effective crisis and post-crisis management which explains the recent interest for real time predictions systems. Nevertheless, this kind of system, when fully implemented with in-situ monitoring network, meteorological forecast inputs, hydrological and hydraulic modelling and flood mapping, are often postponed or cancelled because of both their cost and time scale. That is why Prolog Ingénierie and the SyAGE have developed, as an economical and technical sustainable alternative, a tool providing shared access to a real time mapping of current and predicted flooded areas along with a dynamic listing of exposed stakes (such as public buildings, sensible infrastructures, environmental buildings, roads). The update of these maps is performed from the combination of predicted water levels in the river and a flood envelop library (based on 1D/2D hydraulic model results for a wide panel of discharges and hydraulic structures states conditions). This tool has already been implemented on the downstream part of the Yerres River, a tributary of the Seine River in France.
\end{abstract}

\section{Introduction: from meteorological forecasting to flood forecasting}

In a context of climate change and increasing frequency and magnitude of extreme weather events, constantly revealing the limits of individual and collective protection, and calling into question the design bases, monitoring, forecasting, alert and crisis management are the heart of public action that must be implemented to: assure the people security, reduce the direct and indirect consequences due to flood events and allow a return to normal as quickly as possible.

In such situations, the crisis unit(s), being either internal to local community or extended at departmental or regional level, constitute the decision making's centre nerve about actions to engage and human and material resources to be mobilized on the ground.

In this crisis management plan, the access and sharing of cartographic information in real time about both observed and predictable flooded areas and potentially impacted stakes, is a considerable advantage.

It allows to identify the areas and sectors which will have to be rescued or evacuated, and to count their inhabitants, roads that will be cut, the future isolated areas, to locate schools or health facilities to evacuate or on the contrary which may be used to host the victims, to determine the areas at risk of energy stress or communications blackout, etc.
Thus, this mapping information is a valuable tool for crisis management, and should be easily disseminated to all risk's stakeholders: emergency services, municipalities (implementation of safety communal plans - PCS), public institutions managers, actors public and private, local residents, etc.

France has invested and mobilized substantial resources in terms of flood forecasting. Météo-France, SCHAPI (Hydrometeorological and Flood Forecasting Central Service), SPC (Flood Forecasting Service), ensure the monitoring and forecasting of rainfall and floods and the diffusion of warning to those involved in crisis management and the public [1]. This forecast information is often consigned in a newsletter, dealing with overall developments and point estimates (for monitoring network stations) regarding flow rates and water levels. Maps delimiting the extent of potentially submerged areas are usually not provided.

Paper maps available in crisis units were often produced in Flood Zones 'Atlas (AZI), Flood Risk Prevention Scheme (PPRi), Flood Risk Territories maps (TRI), or specific local studies. The flood events mapped do not always correspond to the event that is currently taking place, the paper format prevents an easy dissemination and sharing of the same information, the stakes are not always represented.

\footnotetext{
${ }^{\mathrm{a}}$ Corresponding author: strappazzon@prolog-ingenierie.fr
} 
The dynamic flood webmapping tool developed by Prolog Ingénierie for the SyAGE is therefore intended to improve the tools and information's vectors on flood risk management in a crisis context, adding to flood forecasting a real time cartographic projection of flooded and potentially flooded areas. This platform could be used by any service in charge of flood risk monitoring and alert at the scale of a homogenous territory: state services, local authorities, rivers 'managers and syndicates,... It was originally built for overflowing rivers 'risk, but its extension to runoff phenomena is clearly possible.

\section{Presentation of the Yerres'watershed and the SyAGE approach in terms of flood management}

The sanitation and water management syndicate of the Yerres valley (SyAGE) has managed the Yerres River since January 1964. The Yerres'watershed, a right bank of the Seine's tributary in the Ile de France region, is both rural upstream and urban downstream.

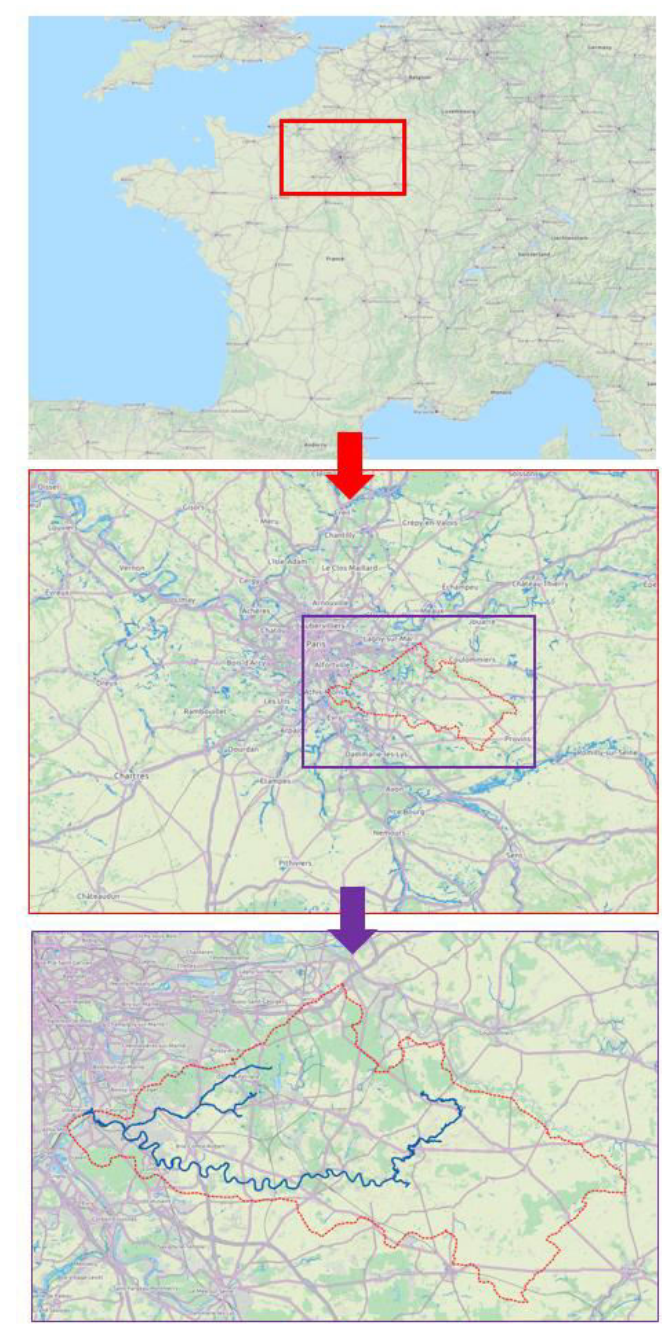

Figure 1. The Yerres'watershed
Among others, the SyAGE goal is to manage runoff and concentration of water, from parcel to river scale. It supports the Scheme of Development and Management of Water and its implementation through two watershed contracts, and has realized since December 2012, a Plan of Actions and Prevention against flooding in the watershed. [2]

This integrated management enables it to operate a variety of measures for flood management, combining optimal environmental issues closely related, such as the restoration of ecological continuity, or restoration of wetlands in floodplains. But flood management needs to go beyond in terms of information sharing, planning, anticipation and coordinated action.

The 100-years return period flood of March 1978 had prompted the SyAGE to build, in the 80 and 90,8 gated weirs to control floods, instead of old weirs originally used for the purposes of milling. Since then, their effectiveness has been proven repeatedly, having helped to contain the river in his natural bed up to a about 10-years return period flood.

Gradually, this hydraulic control for no or low flood events, led the SyAGE to set up in the early 2000s, a centralized supervision of gated weirs in "real time."

Thanks to these operational systems, added to a detailed knowledge of the river system, as well as about forty "hydrometric" measurement stations along the river, the SyAGE continued to develop prevention and alert tools, sharing his knowledge with local actors of the flood (municipalities, emergency services), but also with residents of Yerres valley, with a forecast of about 20 to 24 hours before the spread of flood peak in stakes 'areas.

Through an action program called PAPI, the SyAGE has designed a flood crisis management scenario to test the operability and efficiency of Safety Communal Plans (PCS). On many occasions, it has been tested at the National School of Firemen Officers (ENSOSP) Aix-lesMilles.

In November 2014, during 24 hours, this exercise has been tested at real scale with all the actors of the crisis: Yerres'neighbouring towns of Essonne, Prefecture of Essonne, Departmental Fire and Rescue service, Regional Health Agency, French Red Cross and civil security associations.

The feedback from the majority of the participants underlined the default of anticipation due mainly to the lack of cartographic supports for flooded areas, necessary to decision makers. Therefore, it was necessary to consider the development of a new tool, readable, simple, operational and shared that can meet this demand.

A predictive mapping interface determining the contours of flooded envelops in real time was built. The maps are available through an Internet platform for all actors involved in the flood crisis and are updated regularly by the engineer in charge of the regulation of waterways. 


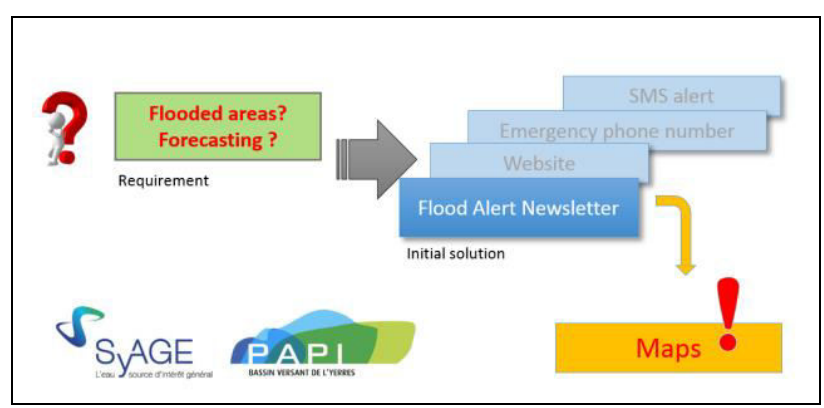

Figure 2. Feedback of crisis management exercise in November 2014

This approach is in coherence with the guidelines defined within the framework of the National Strategy for flood risk management (SNGRI) of May 2014 [3].

\section{Basic requirements for the webmapping platform development}

Many goals have motivated the development and implementation of this webmapping platform:

$\checkmark$ Pragmatism and operability: it was to develop a tool that meets all the needs of actors in crisis management and the needs of decision-making in such situations;

$\checkmark$ Simplicity: it was to develop a simple solution allowing SyAGE's forecasters to disseminate cartographic information from the situation at a moment $\mathrm{T}_{0}$ with little manipulation, and following current procedures;

$\checkmark$ Scalability: flood forecasting on the Yerres basin is difficult because of a complex hydrogeological and hydrological context. The webmapping platform must then be able to follow and adapt to changing systems and digital tools for flood forecasting combined with the strengthening of instrumented measurement network, considered in the context of a future full PAPI (Flood Prevention Actions Program) carried by the SyAGE;

$\checkmark$ Robustness: the platform is intended to disseminate information online to the services of the Prefecture, emergency services, municipalities, etc., and must therefore bear a suitable number of simultaneous connections and provide fallbacks in degraded mode.

\section{Presentation of the webmapping plateform}

\subsection{Platform structure}

The SyAGE goal remains ultimately to implement a comprehensive real time tool for flood. The establishment of this global system is complicated because of the watershed specific hydrogeological context and first requires an important phase of instrumentation.

However, the syndicate expressed the need to quickly implement an operational tool to map flooded areas to help ensure crisis management in case of occurrence of flooding events in the interval leading to the launch of the global system mentioned before in about 2 or 3 years.

To meet these requirements, the developed tool allows to select flooded contours from water levels observed or predicted by SyAGE hydraulic team, based on their local knowledge as well as weather forecasts.

These flooded contours are calculated for vertical 5 $\mathrm{cm}$ resolution, based on modelling results from existing models, built and used in various hydraulic studies [4]. They thus take into account the river geometry, slope changes, different dams monitoring rules, and finely represent overflows, the exploited and previously calibrated models using a two-dimensional approach to the representation of flows in major bed.

These flood maps are then share via a webmapping platform with all SyAGE's partners in crisis management. For each reconstituted flooded area, all the impacted stakes are represented and listed, to provide additional information in the context of crisis management.

\subsection{Study area}

A river linear of $18 \mathrm{~km}$ has been selected for the initial tool deployment along the downstream Yerres, before its confluence with the Seine River. This is the area where most of the human and economic stakes are concentrated, and which is subject to flood levels regulation by gated weirs.

The linear of Yerres in this sector was subdivided into 8 uniform hydraulic sections, ie sections where the water line slope is uniform and is not disturbed by hydraulic structures or discontinuities of the bed morphology. These sections are delimitated by mobile dams.

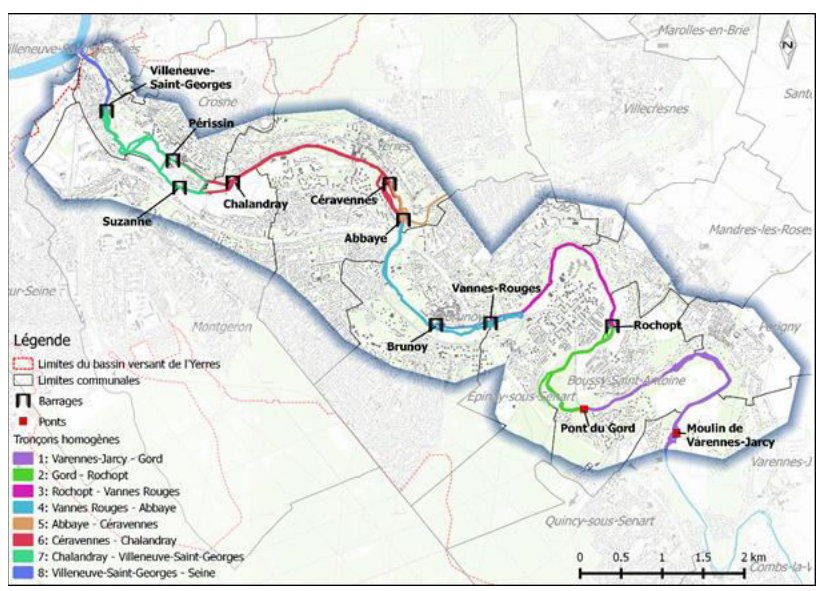

Figure $3.18 \mathrm{~km}$ study area, subdivided into 8 homogenous sections, between SyAGE mobile dams

The SyAGE regulates the water level for each of these sections thanks to gated weirs present along the Yerres riverbed. 
These weirs have an impact on the water level, and therefore on the extent of flooding for low to medium magnitude's events (about 10-years return period event). When the flow of Yerres becomes too great, the dams no longer influence the water line.

\subsection{Webmapping platform's components and performance}

The platform is based on three main components:

$\checkmark$ a flooded areas' library aggregating, by homogeneous section of the Yerres, all potential flood contours, for all possible water levels of the river (every $5 \mathrm{~cm}$ ) between the discharge flow at which Yerres begins to overflow (flood return period of 5 years) up to the flow of an exceptional flood (return period 500 to 1000 years);

$\checkmark$ a configuration interface for SyAGE operators, allowing them to input, for each homogeneous section of the Yerres, estimated water levels, upstream and downstream of the section, for a given forecast time ( +12 hours for example);

$\checkmark$ the webmapping platform that allows viewing flooded areas corresponding to the values indicated by the operator of SyAGE and impacted stakes and roads, printing maps in order to effectively guide crisis management, while disseminating the information available to all actors in the crisis.

The couple (downstream level, upstream level) defined by the operator for a given Yerres section allows to select from the library the contours which most accurately represent the future floods to anticipate (for a time frame set by the operator).

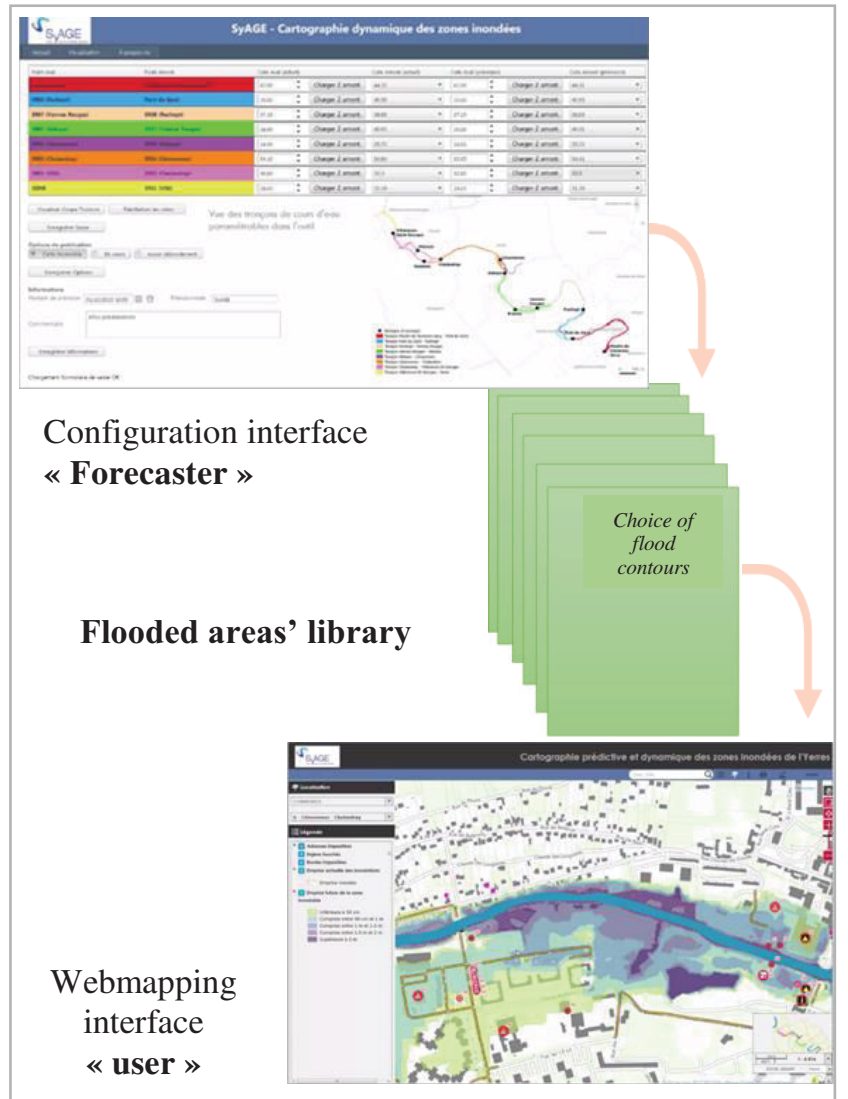

Figure 4. Webmapping's components

\subsubsection{Flood hazard mapping}

The flooded areas' library was filled with flood hazard maps (coupling water levels and water speeds) for the entire range of Yerres flood's flows (action I.4 of Yerres' PAPI). This mapping is based in this case on the results of coupled 1D / 2D hydraulic model of the river. The results have been extracted for all floods for each $5 \mathrm{~cm}$ increase of water level.

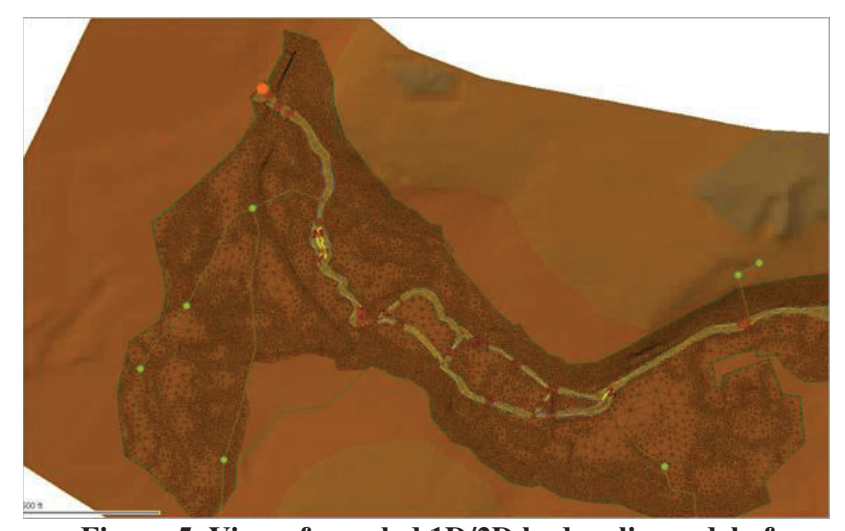

Figure 5. View of coupled 1D/2D hydraulic model of downstream Yerres 


\subsubsection{Stakes mapping}

Collection and checking of socio-economic stakes data was also carried out as part of the action I.4 of PAPI. The stakes were mapped according to recommended thematic under the Flood Directive (human health, economic, environmental, heritage).

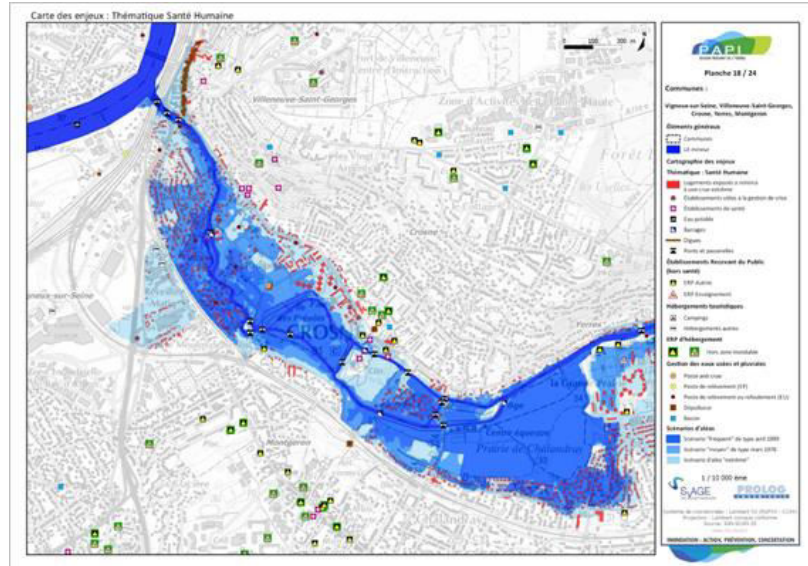

Figure 6. Exemple of « human health » stakes' mapping on downstream Yerres

\subsubsection{Webmapping platform use}

The main flood period in the catchment area of the Yerres corresponds to the winter and spring (November to April usually). Over this period, the SyAGE staff performs weather forecasts monitoring and follows the flood vigilance conducted by the state services on a reference station located in the first third of the river. When a sufficiently intense flood is announced, the mapping platform is open, in parallel with other warning means mobilized by the SyAGE (bulletin, website, email and sms alerts, etc.).

The plateform then works as follow:

1. The on-call forecaster enters the water level measured at $T_{0}$ downstream of each of the 8 hydraulic sections (manual input of 8 values in the entry form).

$\mathrm{He}$ is then offered five possible upstream water level values, these values depending on flow and dams 'regulation, he chose the most appropriate value.

$\mathrm{He}$ performs the same operations but making a prediction of evolution of the situation at $\mathrm{T}+\mathrm{X}$ hours $(6 \mathrm{H}, 12 \mathrm{H} \ldots)$.

$\mathrm{He}$ can also leave several comments on the situation.

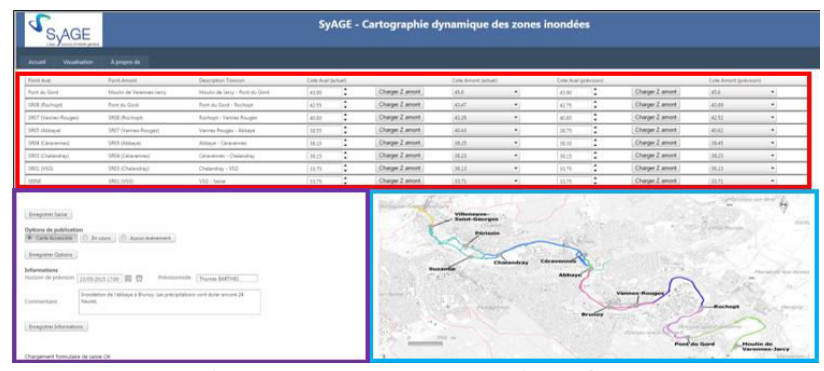

Figure 7. Forecast entry interface
2. The platform will select in the flooded areas' library the map corresponding to the water level couple (downstream / upstream) indicated by the operator for $\mathrm{T}_{0}$ and $\mathrm{T}+\mathrm{X}$ hours.

An automatic selection of certain categories of stakes (sensitive and useful for crisis management: city hall, rescue centers, public buildings, schools, roads, etc.) then allows to integrate the mapping of human and economic stakes exposed.

3. After checking his entry, forecasts and map obtained, this last can be brought online by the forecaster.

It is then accessible on a secure mapping server installed in the SyAGE building, via IDs delivered to all crisis actors (municipalities, rescue services, prefecture, network operators, etc.).

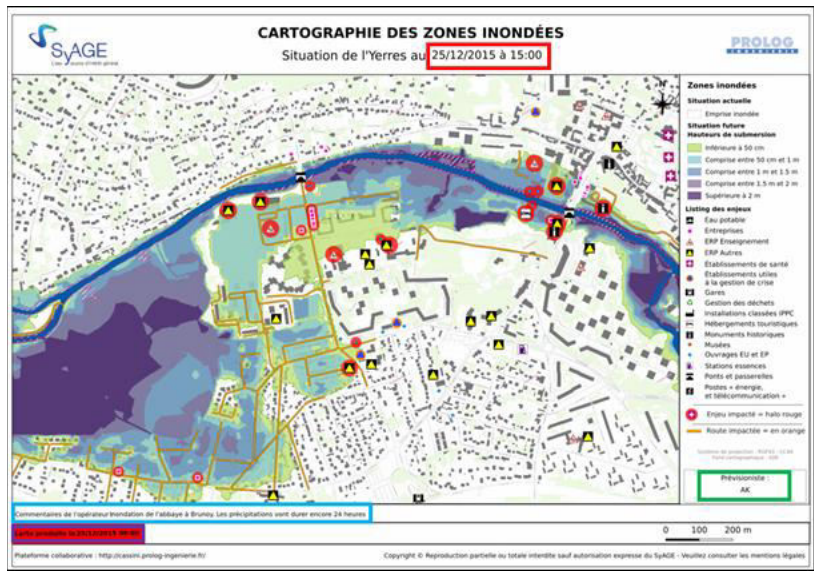

Figure 8. Flooded areas viewing's interface

Additional tools allow to export and print map views in different formats and scales, as well as summary tables of the flooded stakes.

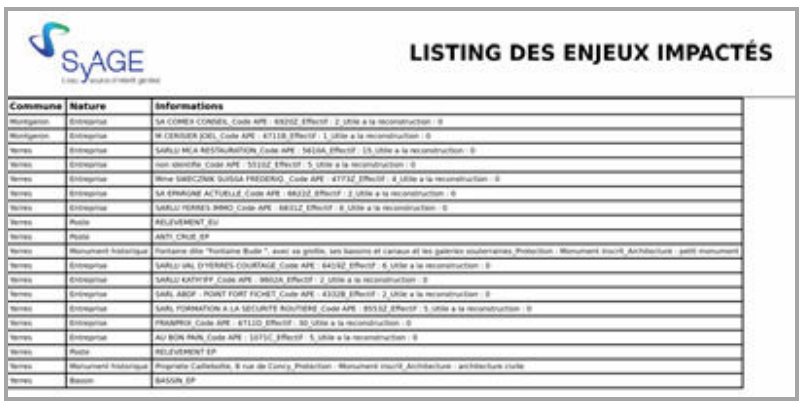

Figure 9. Exemple of impacted stake's listing for a given flooded area

\subsection{Computing requirement}

The mapping platform has been developed using only free tools and open source software:

$\checkmark$ a PostGIS spatial database server to make the connection between the flooded areas' library, the input interface and the mapping platform;

$\checkmark$ software Geographic Information System (GIS) QuantumGIS for construction of maps; 
$\checkmark \quad$ the Lizmap module for the publication of these maps online through a map server;

$\checkmark \quad$ Apache and IIS web servers for hosting the tool.

This choice allows to drastically reduce development costs and offers more freedom in the adjustment features.

The partners of SyAGE were each given a username and password allowing them to connect to the tool, which is hosted directly on the SyAGE internal network to secure the system.

\section{Advantages of real time flood webmapping tool}

The developed platform:

$\checkmark$ is innovative, because different sources of data and information (flooded areas, stakes, roads), that are usually difficult to mobilize and analyse simultaneously at time $\mathrm{T}$, are grouped and aggregated in a single operational tool. The data used are conventional (results of hydraulic models, stakes database and roads), but their development is innovative through a shared tool (all authorized users have access to the same information at the same time), and also integrated tool to visualize in real time the expected consequences of a flood based on forecast predictions, all at a reduced cost;

$\checkmark$ has a strong local impact since it promotes coordination between the various local actors in crisis management (emergency services, police, prefecture, municipalities) who all get the same information via the platform . This shared platform also allows elected officials to involve more municipalities in the crisis management process by giving them the means to assess the seriousness of a flood on their territory and therefore to ensure the protection of their citizens by the implementation of their Backup Communal Plan (PCS). In addition, integration of stakes and roads impacted by flood in the tool allow to assess the degree of vulnerability of the territory locally and thus to implement appropriate organizational measures. The tool helps to improve knowledge of the territory and its risk exposure and can be expanded at any time with new databases (addresses, substations, Waste Treatment Plant, etc. ...);

$\checkmark$ is easily reproducible: the only prerequisite to the development of such a tool at the scale of a watershed are indeed to have a network of hydrometric measurements or a hydraulic model and stakes' databases (information that can be collected within national and local databases with free access via trade agreements, especially with the SDIS, which have databases on public buildings, etc.).
Various projects aiming to facilitate the sharing of information and open data to the greatest number are also underway, in particular:

$\checkmark$ Open data projects, initiated by State and by several metropoles [5];

$\checkmark$ BANO project (Open National Addresses Database) initiated by OpenStreetMap France [6];

$\checkmark$ ERP (public sensitive building) database projects managed by SDIS ;

$\checkmark \quad$ Cartorisque for natural risks [7];

$\checkmark$ Etc.

Thus, such a tool is coherent with the recent logic of information sharing and re-use of data produced.

\section{Evolution of the webmapping platform}

The platform developed for the SyAGE is the first operational step of the expected supervision system evolution to an expert flood forecasting system, as it is planned to develop over the period 2017-2018 in the future full PAPI program.

\section{Acknowledgement}

The team Rivers / Risks thanks the SyAGE for their trust and support, and for offering him the opportunity to participate as observers in the crisis management exercise in November 2014.

\section{References}

1. Service Central d'Hydrométéorologie et d'Appui à la Prévision des Crues (SCHAPI) (2010). Le dispositif de l'Etat pour la surveillance et la prévision des crues - De la collecte de l'information à l'alerte des populations. Lien :

www.vigicrues.gouv.fr/ftp/aide/Maq_VigiCrue_v2A. pdf)

2. SyAGE (2012). PAPI d'intention du bassin versant de l'Yerres - Dossier de candidature à l'appel à projets PAPI du MEDDE du 17/02/2011. 210 pages + annexes.

3. Ministère de l'Ecologie, du Développement Durable et de l'Energie (2014). Stratégie nationale de gestion des risques d'inondation. 24 pages.

4. SyAGE (2015). PAPI d'intention du bassin versant de l'Yerres - Action I.4 : Diagnostic approfondi et partagé du territoire. Rapports Prolog Ingénierie références 13-111-14 / 13-111-15 / 13-111-16.

5. Opendata France; http://www.opendatafrance.net/

6. Projet BANO, OpenStreetMap France; http://openstreetmap.fr/bano

7. Cartorisque; https://www.data.gouv.fr/fr/datasets/cartorisque30382037/ 